\title{
STATIC FLEXURAL CYCLIC FATIGUE OF TWO ROTARY FILE SYSTEMS (AN IN VITRO STUDY)
}

\author{
Raghdaa A. Abd Elsalami ${ }^{*} B D S$, Sybel M. Moussa² $P h D$, Raef A. Sherif ${ }^{2} P h D$
}

\begin{abstract}
INTRODUCTION: Cyclic fatigue fracture is caused by repeated compressive/tensile stresses that accumulate around the curved rotating file. Many efforts have been made to increase the fracture resistance of Nickel-titanium (NiTi) rotary instruments, such as the use of heattreated alloy, modification of the instrument's cross section and the improvement of surface treatment.

OBJECTIVES: The aim of this study was to compare the static flexural cyclic fatigue of TwoShape (Micro Mega, Besancon, France) rotary file system which is made of T-Wire heat treatment technology and OneShape (Micro Mega, Besancon, France) rotary file system which is made of conventional nickel-titanium alloy.

MATERIALS AND METHODS: Eighteen files from each system were subjected to static cyclic fatigue test. Cyclic fatigue testing was performed in a device which allowed a reproducible position of the instrument inside a custom-made stainless-steel artificial canal. The artificial canal had a curvature of $60^{\circ}$ angle and $5 \mathrm{~mm}$ radius. All instruments were allowed to rotate inside the artificial canal until fracture. Time to fracture (TTF) was recorded using a digital chronometer. The number of cycles to failure (NCF) was calculated. The length of separated fragments was recorded. Data were analysed.

RESULTS: The NCF of TwoShape files (365.909 182.077 ) was statistically significantly higher when compared with the OneShape files $(266.681 \pm 35.218) \mathrm{p}<.05$. While there was no significant difference in the length of separated segments between both systems.

CONCLUSIONS: Within the limitations of this study, the cyclic fatigue resistance of heat treated TwoShape files was significantly higher than the OneShape files. [T-wire] heat treatment drastically enhanced the cyclic fatigue resistance of the file.

KEY WORDS: cyclic fatigue, OneShape, TwoShape, artificial canal, number of cycles to fracture, NiTi rotary files.
\end{abstract}

1.Bachelor of Dentistry, Faculty of Dentistry, Pharos University, Alexandria, Egypt

2.Professor of Endodontics Department, Faculty of Dentistry, University of Alexandria, Alexandria, Egypt

*Corresponding author:

E-mail: raghdaa.eldieb.dentist@outlook.com

\section{INTRODUCTION}

Cleaning and shaping of root canals without having any procedural errors is one of the most important factors to achieve a successful root canal treatment. Instrument separation during root canal treatment is one of the most common problems in endodontics which become a frequent error with the introduction of rotary shaping instruments. In case of stainless-steel instruments, fracture is proceeded by mechanical deformation as unwinding which warrants the operator to discontinue using this instrument (1). Unfortunately, this is not the case of Nickle-Titanium ( $\mathrm{Ni} \mathrm{Ti}$ ) files which could be fractured during function without any previous warning even with new files during their first use. This mechanical failure could be due to either overload or fatigue of the material (2). However, Introduction of Ni Ti rotary instruments has provided easier and faster canal instrumentation and has minimized the procedural errors and operator fatigue (3). Instrument fracture is known to occur due to either forms torsional or flexural cyclic fatigue. Torsional fatigue fracture occurs when an instrument is locked into a canal during rotation and the resulting torque exceeds the elastic limit of the Ni Ti alloy. While Cyclic fatigue fracture is caused by repeated compressive/tensile stresses that accumulate around the curved point of rotating instrument $(4,5)$. 
Heat treatment is one of the modifications that was carried out to improve the file mechanical properties and increase its fracture resistance (6). One Shape (OS) is a single continuous rotating file made of a conventional austenite $\mathrm{Ni} \mathrm{Ti}$ alloy which was introduced in the market 2012 by (Micro Mega, Besancon, France). They have a triangular cutting edge in the apical part, 2 cutting edges in the coronal part, and a cross section that progressively changes from 3 to 2 cutting edges between the apical and coronal parts; this design was supposed to offer better cutting action $(7,8)$.

Two Shape files (Micro Mega, Besancon, France) are manufactured by a proprietary heat treatment (T-Wire) that is claimed to enhance the flexibility and cyclic fatigue resistance of instruments. They have asymmetrical cross section with triple helix which might reduce the risk of instrument fracture, two main cutting edges and one secondary cutting edge for improved debris removal (9).

Cyclic fatigue test is an important test to give the clinician an idea about the cyclic fatigue resistance of the file. This test is performed by allowing files to rotate inside an artificial canal until fracture. For this test, several studies had used different canal's curvatures, methods, designs and modes (10). Cyclic fatigue test can be performed either in static or dynamic mode. In the static mode, the endodontic hand piece is fixed in a reproducible position without any axial movement during the test. Whereas, in the dynamic mode the endodontic hand piece has an axial oscillating motion during the test to simulate a clinical pecking motion with (1-3mm) oscillation amplitude range (10-15).

Cyclic fatigue resistance is affected by every single variable not only the alloy type (heat treatment) but also the instrument's design, cross section, flexibility and motion $(16,17)$. Therefore, the research question of the study is whether the Two-Shape rotary file system will have higher cyclic fatigue resistance than the One-Shape rotary file system. The null hypothesis is that Two-Shape TS2 rotary file (\#25 / 0.06) will not have higher cyclic fatigue resistance than One-Shape rotary file (\#25 / 0.06).

\section{MATERIALS AND METHODS}

A total of thirty-six Ni Ti rotary files of One Shape and Two Shape (Micro Mega, Besancon, France) were tested. All tested files had ISO tip size number 25 and constant taper $6 \%$. Files used in this study were classified into two main groups (each $\mathrm{n}=18$ ) according to file's system; group I (One Shape) and group II (Two Shape) TS2. A special device was constructed for cyclic fatigue testing of endodontic files. This device held the endodontic motor and the artificial canal securely in a reproducible position (Fig.1, Fig.2) All files were allowed to rotate inside a custom-made stainless-steel artificial canal which had the same size and taper of the files to be used plus $0.1 \mathrm{~mm}$ relief circumferentially for the whole file. The canal had a $16 \mathrm{~mm}$ length and $60^{\circ}$ angle of curvature with $5 \mathrm{~mm}$ radius of curvature according to the curvature's definition of Pruett et al., (18) who described the curvature by two parameters [angle and radius of curvature]. Synthetic lubricating oil was used inside the artificial canal to reduce friction during file rotation (Fig.3). Video was recorded for each file during the test. During the file rotation in the canal, file was observed visually and audibly very carefully by the operator until the file was broken (Fig.4). Time to fracture was recorded using digital chronometer $(19,20)$. Times were then multiplied by the endodontic motor speed (350 rpm) to obtain the number of cycles to fracture according to the following formula $(8,14)$ :

NCF $=$ Number of rotations per minutes $(350 \mathrm{rpm}) \times$ Time till fracture (seconds)

Statistical analysis:

After obtaining the number of cycles to fracture (NCF) for all files, data were collected and entered to the computer using SPSS (Statistical Package for Social Science) program for statistical analysis (ver 21) (21). Data were entered as numerical or categorical, as appropriate.

Kolmogorov-Smirnov test of normality revealed significance in the distribution of most of the variables, so the non-parametric statistics was adopted (22).

- Data were described using minimum, maximum, mean, standard deviation and 95\% CI of the mean (23), median and inter-quartile range for not-normally distributed data.

- Comparisons were carried out between two studied independent not-normally distributed subgroups using Mann-Whitney U test (24).

- Box and Whiskers plot was used accordingly.

- An alpha level was set to 5\% with a significance level of $95 \%$, and a beta error accepted up to $20 \%$ with a power of study of $80 \%$.

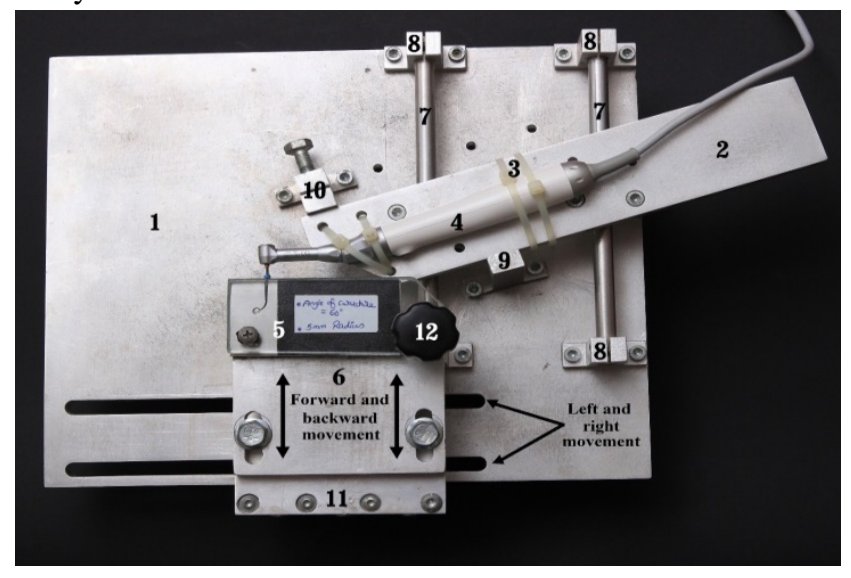


Figure (1): Device top view. $1=$ main plate; $2=$ motor table; $3=$ Plastic tie wraps to hold the endodontic motor tightly; $4=$ endodontic motor (hand piece); $5=$ artificial canal block; $6=$ block bench; $7=$ two round rail motion guides; $8=$ rails supports; $9=$ fixed stopper; $10=$ hinged stopper; 11= part of block bench connection assembly; $12=$ hand screw.

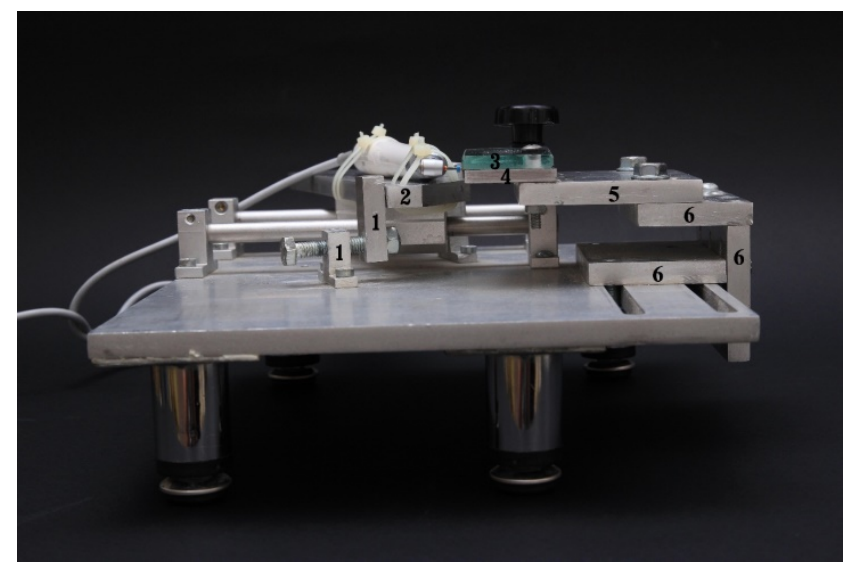

Figure (2): Device side view. 1= hinged stopper; $2=$ motor table; $3=$ glass cover of the canal block; $4=$ artificial canal block; $5=$ block bench; $6=$ three plates together form the block bench connection assembly.

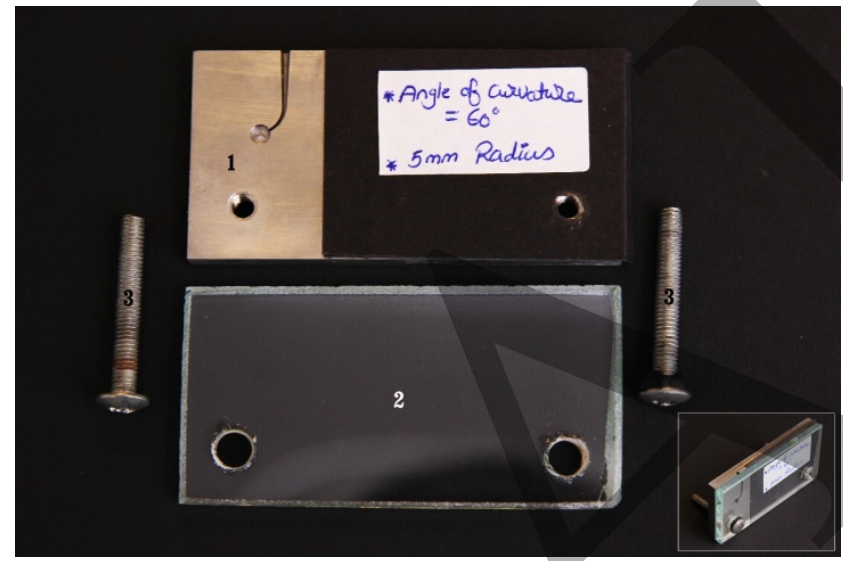

Figure (3): The canal block parts. $1=$ artificial canal block; $2=$ customized glass cover; $3=$ screws to hold the glass cover and canal block together. All these parts assembled together as at the small picture.

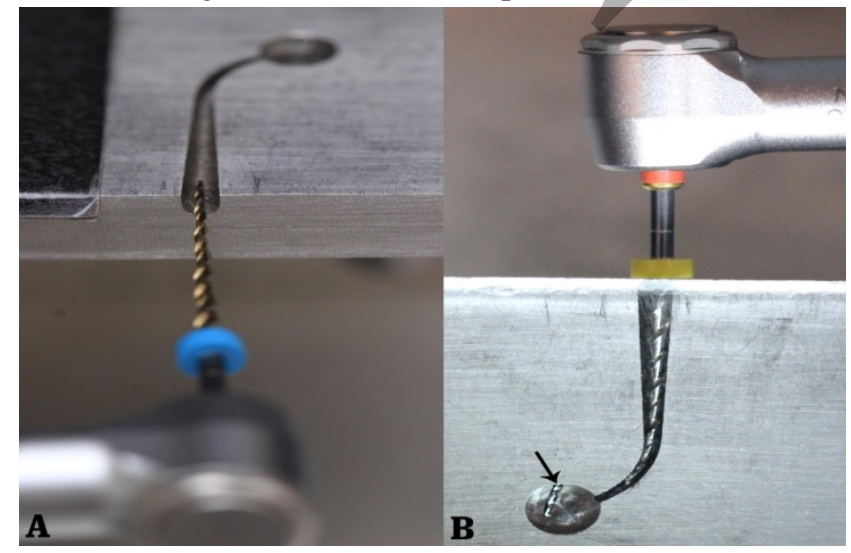

Alexandria Dental Journal. Volume 45 Issue 3.
Figure (4): Side view of the artificial canal. (A) the resemblance of the U-shaped cross section of the artificial canal. (B) file inside the canal, arrow pointing at the broken fragment during the test.

\section{RESULTS}

In the present study, the number of cycles to fracture in One Shape files group ranged from 223.533 to 356.592 with a mean \pm SD of $266.681 \pm 35.218$ (95\% CI for mean of 249.16692-284.19430) with a median (IQR) 259.759 (237.708-282.217). While in the Two Shape files group it ranged from 241.850 to 611.742 with a mean \pm SD of $365.909 \pm 82.077$ (95\% CI for mean of 325.09311406.72466) with a median (IQR) 358.925 (326.317372.633). The number of cycles to fracture in Two Shape files group was statistically significantly higher when compared with the One Shape files $(\mathrm{Z}=4.303, \mathrm{p}=0.000)$ (Table1, Figure 5).

In the present study, the length of separated fragment in the One Shape files group ranged from 2.0 to $3.0 \mathrm{~mm}$ with a mean \pm SD of $2.6 \pm 0.3 \mathrm{~mm}$ (95\% CI for mean of 2.461-2.784 mm) with a median (IQR) 2.7 (2.32.9) $\mathrm{mm}$. While in the Two Shape files group it ranged from 2.0 to $3.1 \mathrm{~mm}$ with a mean \pm SD of $2.4 \pm 0.3 \mathrm{~mm}$ (95\% CI for mean of 2.296-2.593 mm) with a median (IQR) $2.5 \quad(2.2-2.6) \mathrm{mm}$. There was no significant difference in the length of separated fragment between the two tested groups ( $\mathrm{Z}=1.756, \mathrm{p}=0.085$ ) (Table 2, Figure 6).

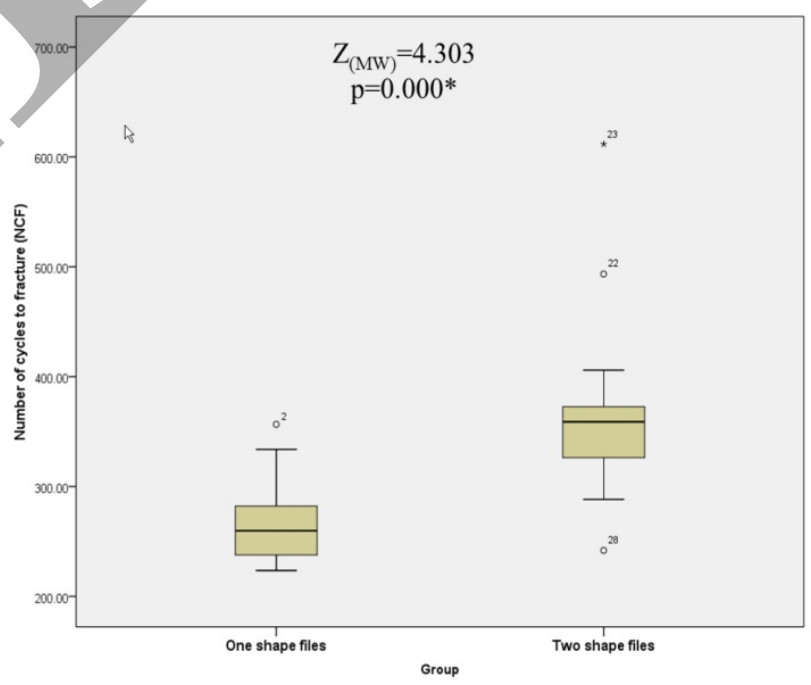

Figure (5): Box and whisker graph of number of cycles to fracture (NCF) in the studied groups, the thick line in the middle of the box represents the median, the box represents the inter-quartile range (from $25^{\text {th }}$ to $75^{\text {th }}$ percentiles), and the whiskers represent the minimum and maximum after excluding outliers (black circles) and extremes (black asterisks). Numbers indicate file number in the original master table 


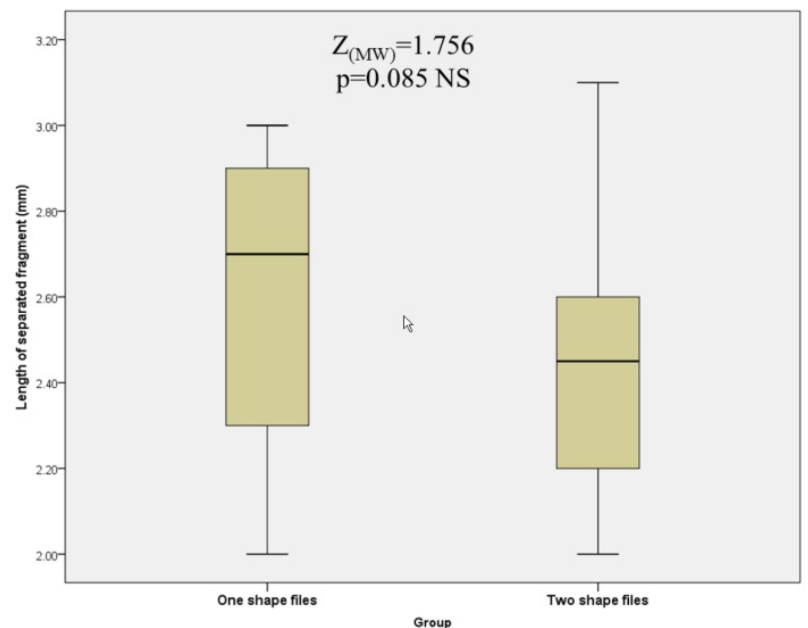

Figure (6): Box and whisker graph of length of separated fragment (mm) in the studied groups, the thick line in the middle of the box represents the median, the box represents the inter-quartile range (from $25^{\text {th }}$ to $75^{\text {th }}$ percentiles), and the whiskers represent the minimum and maximum.

Table (1): Number of cycles to fracture in the two tested groups

\begin{tabular}{|c|c|c|c|}
\hline $\begin{array}{l}\text { Numbe } \\
\mathrm{r} \text { of } \\
\text { cycles } \\
\text { to } \\
\text { fracture } \\
\text { (NCF) }\end{array}$ & OneShape files & $\begin{array}{l}\text { TwoShape } \\
\text { files }\end{array}$ & $\begin{array}{l}\text { Test of } \\
\text { significanc } \\
\text { e }\end{array}$ \\
\hline $\begin{array}{l}\text { n } \\
\text { Min- } \\
\text { Max } \\
\text { Mean } \pm \\
\text { Std. } \\
\text { Deviati } \\
\text { on } \\
95 \% \text { CI } \\
\text { for } \\
\text { mean } \\
\text { Median } \\
\text { (IQR) } \\
\text { KS test } \\
\text { of } \\
\text { normali } \\
\text { ty }\end{array}$ & $\begin{array}{l}18 \\
223.533- \\
356.592 \\
266.681 \pm 35.21 \\
8 \\
249.16692- \\
284.19430 \\
259.759 \\
(237.708- \\
282.217) \\
D=0.144, \\
p=0.200 \text { NS }\end{array}$ & $\begin{array}{l}18 \\
241.850- \\
611.742 \\
365.909 \pm 82 . \\
077 \\
325.09311- \\
406.72466 \\
358.925 \\
(326.317- \\
372.633) \\
D=0.245 \\
p=0.005^{*}\end{array}$ & $\begin{array}{l}\square(\mathrm{MW})=4.3 \\
03 \\
p=0.000 *\end{array}$ \\
\hline
\end{tabular}

$\mathrm{n}:$ Number of files

Min-Max: Minimum - Maximum

CI: Confidence interval

IQR: Inter-quartile range

KS: Kolmogorov-Smirnov

MW: Mann-Whitney U test

* : Statistically significant $(\mathrm{p}<0.05)$

NS: Statistically not significant $(\mathrm{p} \geq 0.05)$

Alexandria Dental Journal. Volume 45 Issue 3.
Table (2): Length of separated fragment in the two tested groups

\begin{tabular}{|l|l|l|l||}
\hline $\begin{array}{l}\text { Length of } \\
\text { separated } \\
\text { fragment } \\
\text { (mm) }\end{array}$ & $\begin{array}{l}\text { OneShape } \\
\text { files }\end{array}$ & $\begin{array}{l}\text { TwoShape } \\
\text { files }\end{array}$ & $\begin{array}{l}\text { Test of } \\
\text { significance }\end{array}$ \\
\hline $\mathrm{n}$ & 18 & 18 & \\
Min-Max & $2.0-3.0$ & $2.0-3.1$ & \\
Mean \pm Std. & $2.6 \pm 0.3$ & $2.4 \pm 0.3$ & $\square(\mathrm{MW})=1.756$ \\
Deviation & $2.461-$ & $2.296-$ & $p=0.085 \mathrm{NS}$ \\
$95 \%$ CI for & 2.784 & 2.593 \\
mean & $2.7 \quad(2.3-$ & $2.5 \quad(2.2-$ & \\
Median & $2.9)$ & $2.6)$ & \\
(IQR) & $\mathrm{D}=0.208$, & $\mathrm{D}=0.135$ & $\mathrm{p}=0.200$ \\
KS test of & $\mathrm{p}=0.038^{*}$ & $\mathrm{NS}$ & \\
normality & &
\end{tabular}

$\mathrm{n}$ : Number of files

Min-Max: Minimum - Maximum

CI: Confidence interval

IQR: Inter-quartile range

KS: Kolmogorov-Smirnov

MW: Mann-Whitney U test

* : Statistically significant $(\mathrm{p}<0.05)$

NS: Statistically not significant $(\mathrm{p} \geq 0.05)$

\section{DISCUSSION}

This study was performed to compare between the static flexural cyclic fatigue of One Shape and Two Shape files. Instrument separation is a serious complication which might happen during root canal treatment. Many efforts were done to investigate the most causative factor of file separation. The manufacturers had continuous evaluation and improvement of the instrument to produce a flexible file which had sufficient strength and centering ability. These mechanical properties of the instrument would allow the practitioner to have canal preparation without procedural errors such as: canal transportation, zipping, ledge formation and file separation.

Cyclic fatigue test is an important test to give the clinician an idea about the cyclic fatigue resistance of the file. The major drawback of most laboratory studies that have tested the fatigue behavior of $\mathrm{Ni}$ Ti rotary instruments is that all of the different contributing factors such as (instrument cross-section, design, material and dimensions) can't be totally eliminated. This makes it difficult to quantify the effect of a single variable on fatigue behavior.

The ideal model to resemble the clinical situation for In-Vitro cyclic fatigue test is allowing files to rotate inside curved canals of natural teeth. However, the usage 
of natural teeth will make it impossible to standardize the experimental condition as the natural canal geometry will be changed during preparation and could be used only one time. The use of standardized artificial canals in cyclic fatigue experiments minimizes the influence of other variables not related to the instrument itself. Artificial canals with definite geometry and curvature had been used for this test.

In this study a special device was designed and constructed for cyclic fatigue testing of endodontic files. This device have the following objectives: the first is to hold the endodontic motor and the artificial canal securely in a reproducible position, the second is to reproduce the exact position of the file in the artificial canal after changing the file between different samples, the third is to allow accurate positioning of the file in the artificial canal. Aluminum mold alloy was used as the raw material for construction. It has the advantages of high strength and stiffness and low weight. The design of this device allows accurate positioning of the canal in relation to the file. The motor table which hold the endodontic handpiece had different holes to allow the usage of the plastic tie warps for accurate fixation of the handpiece during testing.

The artificial canal was designed corresponding to the size and taper of the tested files from both systems (\#25.06) plus $0.1 \mathrm{~mm}$ relief circumferentially for the whole file, allowing the instrument to rotate freely inside the artificial canal. This design precisely constrained the file in a suitable trajectory during the test. The $0.1 \mathrm{~mm}$ amount of relief was chosen as according to Plotino et al., (25) who tested three different canals, the amount of $0.1 \mathrm{~mm}$ relief was the best design in which the tested file respect the established parameters of the canal's curvature, while the relief of $0.3 \mathrm{~mm}$ and the non-tapered canals can't precisely constrain the file in the established parameters.

All the parameters (Angle, radius of the curvature and position of the center of the curvature) are controlled by the researcher before the construction of the artificial canal. Computerized aided design (CAD) was performed for canal construction and then milling of the artificial canal in a stainless-steel block was done. After that, the block is hard Chrome electroplated to increase the block hardness so it would not be milled down by the files during testing. In this study, videos recorded for all files during the test. Re-evaluation of the time to fracture was done after a period of two weeks from the first evaluation to provide an intra-observer reliability. The artificial canal had $60^{\circ}$ angle, $5 \mathrm{~mm}$ radius of curvature and maximum convexity is $5 \mathrm{~mm}$ from the tip of the canal. These specific parameters were chosen as most of the cyclic fatigue studies used them $(26,27)$.

Alexandria Dental Journal. Volume 45 Issue 3.
In our study the device worked at static mode without any axial movement (28). The static mode was chosen as according to Keles et al., (29) the dynamic axial movement resulted in an extended cyclic fatigue life.

Lack of standardization for cyclic fatigue testing led researchers to try developing standardized techniques and methods for fatigue testing of endodontic instruments. All these techniques allow files to rotate at certain parameters and record the duration from the beginning of rotation until breakage of the file. These different techniques seem trying to achieve two goals: the first is to control accurately different variables during the test so the variation in the results would be due to variation in the cyclic fatigue resistance of files under testing and not a result of uncontrolled variables, the second is to imitate the clinical condition as much as possible. Standardization could be as simple as standardizing the file position inside the canal, file size, canal (size and taper), position of the endodontic hand piece in relation to the canal and (speed $\&$ torque) of the endodontic motor.

In our study, standardization was achieved by testing both systems inside the same artificial canal, device, environment (room temperature), files size (25.06), rotational motion (continuous rotation), endodontic motor speed $(350 \mathrm{rpm})$ and torque $(2.5 \mathrm{N.cm})$. This torque and speed were used according to the manufacturer recommendations. The aim of standardization was to exclude any contributing causative factors except for the point of difference between the tested files which was the heat treatment.

In this study, the test was performed at room temperature with interval period of (20 minutes) between each tested file and synthetic oil was used inside the artificial canal for lubrication of the rotating file inside the canal and to avoid the effect of the generated heat in the metal block during testing. According to Dosanjah et al., (30) increasing the environmental temperature drastically decrease the number of cycles to fracture.

In our study we compared the TS and OS files to investigate the effect of [T-Wire] recent proprietary heat treatment in the cyclic fatigue resistance of the file. Our results showed that TwoShape files had greater number of cycles to fracture compared with OneShape files. This might be due to the difference in the metal alloy as OneShape files are manufactured from conventional NiTi wire, while TwoShape files are manufactured from heat treated T-wire. TwoShape files have two main cutting edges and one secondary cutting edge for improved debris removal. while OneShape files have cross section that progressively changes from 3 to 2 cutting edges from the apical to coronal parts. Our results showed that there was no significant difference in the length of separated 
fragments between both tested systems. Thus, both systems revealed the same file's fracture level (apical third) at which the tested file had three cutting edges. This making us excluded the file's cross section as causative factor of the resulted difference in the cyclic fatigue resistance between the two files systems. The crosssectional area of the file has a significant effect in the cyclic fatigue resistance as Sekar et al., (26) found that the smaller cross-sectional area of the file, the greater cyclic resistance would be. In the results of our study, we found one specimen from OneShape (\#2) and three specimens from TwoShape (\#22, \#23 and \#28) at the specimen distribution were outliers (had extreme reading), we attributed that to the manufactural defects.

In agreement with our results, Ataya et al., (31)

found T-Wire heat treatment drastically enhanced the cyclic fatigue resistance of heat-treated OneFlare files when compared with conventional OneFlare files. Whereas, Sekar et al., (26) found that M-two files had higher cyclic fatigue resistance than OS. Moreover, Gündoğar \& Özyürek (32) found that The HyFlex EDM files had the greatest number of cycles to fracture while the OS files had the least among all tested files. Furthermore, Staffoli et al., (33) found that OneCurve files had higher cyclic fatigue resistance than both OS and OneShape new generation. Uslu et al., (34) found that TS files had the highest cyclic fatigue resistance among all tested files. As well, Neelakantan et al., (35) found that Reciproc (R25) had greater number of cycles to fracture than OneShape files at both static and dynamic modes. likewise, Serafin et al., (36) found that OneCurve files had greater cyclic fatigue resistance than OneShape. Also, Topcuoglu et al., (37) found that HyFlex CM and ProTaper Next (X2) files had higher cyclic fatigue resistance than both OnShape and ProTaper Universal (F2) files

In the contrary, Wang et al., (38) found that OneShape files had higher cyclic fatigue resistance than ProTaper Universal (F2) files when files tested in canals with $60^{\circ}$ and $90^{\circ}$ angle of curvature.

The limitation of this study was that before cyclic fatigue testing, we did not examine files by scanning electron microscope or stereomicroscope for exclusion of files with manufactural defects before testing.

\section{CONCLUSION}

Within the limitations of this study, TwoShape files which were made of T-Wire had significantly higher cyclic fatigue resistance when compared with OneShape files which were made of conventional NiTi alloy. Heat treatment drastically affected the cyclic fatigue resistance of the instrument.

\section{Conflict Of Interest}

Alexandria Dental Journal. Volume 45 Issue 3.
The authors declare that they have no conflict of interest.

\section{REFERENCES}

1. Chernick LB, Jacobs JJ, Lautenschlager EP, Heuer MA. Torsional failure of endodontic files. J Endod. 1976;2:94-7.

2. Ullmann CJ, Peters OA. Effect of cyclic fatigue on static fracture loads in ProTaper nickel-titanium rotary instruments. J Endod. 2005;31:183-6.

3. Mokhtari H, Niknami M, Sohrabi A, Habibivand E, Mokhtari Zonouzi HR, Rahimi S, et al. Cone-beam computed tomography comparison of canal transportation after preparation with biorace and mtwo rotary instruments and hand K-flexofiles. Iran Endod J. 2014;9:180-4.

4. Sattapan B, Nervo GJ, Palamara JE, Messer HH. Defects in rotary nickel-titanium files after clinical use. J Endod. 2000;26:161-5.

5. Tokita D, Ebihara A, Miyara K, Okiji T. Dynamic torsional and cyclic fracture behavior of ProFile rotary instruments at continuous or reciprocating rotation as visualized with high-speed digital video imaging. J Endod. 2017;43:1337-42.

6. Goo HJ, Kwak SW, Ha JH, Pedullà E, Kim HC. Mechanical properties of various heat-treated nickeltitanium rotary instruments. J Endod. 2017;43:1872-7.

7. Sharma $P$, Goel M, Verma S. entering a new era in endodontics with revolutionary single file systems: A comprehensive review. EC Dental Sci. 2016;5:1100-22.

8. Topçuoğlu HS, Topçuoğlu G, Akti A, Düzgün S. In vitro comparison of cyclic fatigue resistance of ProTaper Next, HyFlex CM, OneShape, and ProTaper Universal instruments in a canal with a double curvature. J Endod. 2016;42:969-71.

9. 2Shape, séquence de 2 instruments de mise en forme en rotation continue. 2017. Available at: http://micromega.com/shaping/2shape.

10. Plotino G, Grande NM, Cordaro M, Testarelli L, Gambarini G. A review of cyclic fatigue testing of nickel-titanium rotary instruments. J Endod. 2009;35:1469-76.

11. De-Deus G, Vieira VT, da Silva EJ, Lopes H, Elias CN, Moreira EJ. Bending resistance and dynamic and static cyclic fatigue life of Reciproc and WaveOne large instruments. J Endod. 2014;40:575-9.

12. Higuera O, Plotino G, Tocci L, Carrillo G, Gambarini G, Jaramillo DE. Cyclic fatigue resistance of 3 different nickel-titanium reciprocating instruments in artificial canals. J Endod. 2015;41:913-5.

13. Adıgüzel M, Capar ID. Comparison of cyclic fatigue resistance of WaveOne and WaveOne Gold small, primary, and large instruments. J Endod. 2017;43:623-7. 
14. Alcalde MP, Tanomaru-Filho M, Bramante CM, Duarte MA, Guerreiro-Tanomaru JM, Camilo-Pinto J, et al. Cyclic and torsional fatigue resistance of reciprocating single files manufactured by different nickel-titanium alloys. J Endod. 2017;43:1186-91.

15. Keskin C, Inan U, Demiral M, Keleş A. Cyclic fatigue resistance of Reciproc Blue, Reciproc, and WaveOne Gold reciprocating instruments. J Endod. 2017;43:1360-3.

16. Testarelli L, Plotino G, Al-Sudani D, Vincenzi V, Giansiracusa A, Grande NM, et al. Bending properties of a new nickel-titanium alloy with a lower percent by weight of nickel. J Endod. 2011;37:1293-5.

17. Lopes HP, Gambarra-Soares T, Elias CN, Siqueira Jr JF, Inojosa IF, Lopes WS, et al. Comparison of the mechanical properties of rotary instruments made of conventional nickel-titanium wire, M-wire, or nickeltitanium alloy in R-phase. J Endod. 2013;39:516-20.

18. Pruett JP, Clement DJ, Carnes DL. Cyclic fatigue testing of nickel titanium endodontic instruments. J Endod. 1997;23:77-85.

19. Inan U, Aydin C, Demirkaya K. Cyclic fatigue resistance of new and used Mtwo rotary nickel-titanium instruments in two different radii of curvature. Aust Endod J. 2011;37:105-8.

20. Özyürek T. Cyclic fatigue resistance of Reciproc, WaveOne, and WaveOne Gold nickel-titanium instruments. J Endod. 2016;42:1536-9.

21.IBM Corp. IBM SPSS Statistics for Windows, Version 21.0. Armonk, NY: IBM Corp.; Released 2012.

22. Field A. Discovering Statistics Using IBM SPSS Statistics. $4^{\text {th }}$ ed. London, California, New Delhi: SAGE Publications Ltd; 2013.

23. Snecdecor GW, Cochran WG. Statistical Methods: Chapter 2: The Mean and Standard Deviation. Wiley; 1991; 14-29.

24. Mann HB, Whitney DR. On a test of whether one of two random variables is stochastically larger than the other. Ann Math Stat. 1947;50-60.

25. Plotino G, Grande NM, Mazza C, Petrovic R, Testarelli L, Gambarini G. Influence of size and taper of artificial canals on the trajectory of NiTi rotary instruments in cyclic fatigue studies. Oral Surg Oral Med Oral Pathol Oral Radiol Endod. 2010;109:e60-6.

26. Sekar V, Kumar R, Nandini S, Ballal S, Velmurugan N. Assessment of the role of cross section on fatigue resistance of rotary files when used in reciprocation. Eur J Dent. 2016;10:541-5.

27. Uslu G, Özyürek T, İnan U. Comparison of cyclic fatigue resistance of ProGlider and one $G$ glide path files. J Endod. 2016;42:1555-8.
28. Yılmaz K, Özyürek T. Cyclic fatigue life of TangoEndo, WaveOne GOLD, and reciproc NiTi instruments. Restor Dent Endod. 2017;42:134-9.

29. Keleş A, Eymirli A, Uyanık O, Nagas E. Influence of static and dynamic cyclic fatigue tests on the lifespan of four reciprocating systems at different temperatures. Int Endod J. 2019;52:880-6.

30. Dosanjh A, Paurazas S, Askar M. The effect of temperature on cyclic fatigue of Nickel-titanium rotary endodontic instruments. J Endod. 2017;43:823-6.

31. Ataya M, Ha JH, Kwak SW, Abu-Tahun IH, El Abed R, Kim HC. Mechanical Properties of Orifice Preflaring Nickel-titanium Rotary Instrument Heat Treated Using T-Wire Technology. J Endod. 2018;44:1867-71.

32. Gündoğar M, Özyürek T. Cyclic fatigue resistance of OneShape, HyFlex EDM, WaveOne gold, and Reciproc blue nickel-titanium instruments. J Endod. 2017;43:1192-6.

33. Staffoli S, Grande NM, Plotino G, Özyürek T, Gündoğar $\mathrm{M}$, Fortunato $\mathrm{L}$, et al. Influence of environmental temperature, heat-treatment and design on the cyclic fatigue resistance of three generations of a single-file nickel-titanium rotary instrument. Odontology. 2019;107:301-7.

34. Uslu G, Özyürek T, Gündoğar M, Yılmaz K. Cyclic fatigue resistance of 2Shape, Twisted File and EndoSequence Xpress nickel-titanium rotary files at intracanal temperature. J Dent Res Dent Clin Dent Prospects. 2018;12:283-7.

35. Neelakantan P, Reddy P, Gutmann JL. Cyclic fatigue of two different single files with varying kinematics in a simulated double-curved canal. J Investig Clin Dent. 2016;7:272-7.

36. Serafin M, De Biasi M, Franco V, Angerame D. In vitro comparison of cyclic fatigue resistance of two rotary single-file endodontic systems: OneCurve versus OneShape. Odontology. 2019 Apr 15;107(2):196-201.

37. Topçuoğlu HS, Topçuoğlu G, Akti A, Düzgün S. In vitro comparison of cyclic fatigue resistance of ProTaper Next, HyFlex CM, OneShape, and ProTaper Universal instruments in a canal with a double curvature. J Endod. 2016 Jun 1;42(6):969-71.

38. Wang Z, Zhang W, Zhang X. Cyclic Fatigue Resistance and Force Generated by OneShape Instruments during Curved Canal Preparation. PloS one. 2016;11:e0160815. 